\title{
Carbon deposition map for nickel particles onto oxide substrates analyzed by micro-Raman spectroscopy
}

\author{
Masashi YOSHINAGA, ${ }^{*}$ Haruo KISHIMOTO, ${ }^{* \dagger}$ Manuel E. BRITO,${ }^{*}$ Katsuhiko YAMAJI, ${ }^{*}$ \\ Teruhisa HORITA* and Harumi YOKOKAWA ${ }^{*, * *}$ \\ *National Institute of Advanced Industrial Science and Technology (AIST), \\ AIST Tsukuba Central 5, Higashi 1-1-1, Tsukuba, Ibaraki 305-8565 \\ ${ }^{* *}$ Tokyo City University, Todoroki 8-15-1, Setagaya-ku, Tokyo 158-0082
}

Distribution maps of carbon deposited on nickel particles were obtained by micro-Raman spectroscopy. Nickel film was prepared on the oxide substrates of yttria stabilized zirconia (YSZ) and gadolinia doped ceria (GDC). Carbon deposition was induced by annealing in dry methane for $10 \mathrm{~min}$ at both 863 and $933 \mathrm{~K}$. Morphology of nickel film was changed into particles with the size of several ten-nanometer to several micrometer at the edge of the nickel film after annealing. For the nickel/YSZ systems, carbon thoroughly deposited on all of sintered nickel particles but was not observed on YSZ surface. For the nickel/GDC systems, carbon was deposited only on the nickel particles with sub-micrometer size.

(C2011 The Ceramic Society of Japan. All rights reserved.

Key-words : Micro-Raman spectroscopy, Carbon deposition, Nickel particle, Triple phase boundary (TPB), Solid oxide fuel cell (SOFC)

[Received February 2, 2011; Accepted February 13, 2011]

\section{Introduction}

Solid oxide fuel cells (SOFCs) are one of the most efficient electric power generation systems. In SOFCs, ceramic-metal composites, such as nickel-zirconia cermet, has been used as anode material. ${ }^{1)}$ Porous structure of nickel (Ni)-oxide cermet is formed by connected networks of each component with the particle size of several hundred nanometer to several micrometer, generally. Due to its complex structure, it is very difficult to clarify the properties of cermet anode, especially the electrochemical properties at the gas/nickel/oxide triple phase boundaries (TPBs) and degradation behavior. One of the effective ways to clarify the TPB property is to produce model electrodes, in which TPB length and electrode surface area are clearly determined. ${ }^{2)-6)}$ Mizusaki et al. reported detailed analysis of electrode reaction mechanism by using model electrode.2),3) Kawada et al. used a modified model electrode to reveal the carbon deposition behavior on nickel and platinum electrode surfaces. ${ }^{5), 6)}$ They reported that oxidation of deposited carbon on the electrode surface started from the TPB under anodic polarization condition. ${ }^{5)}$

Carbon deposition, due to principally thermal decomposition of hydrocarbons, on the Ni-base anodes is one of the most serious degradation for hydrocarbon fueled SOFCs and, in more critical cases, that leads to anode disintegration. ${ }^{7), 8)}$ To set strategies to prevent anode degradation associated to the carbon deposition, it is important to clarify the carbon deposition behavior at the early stage and the nature of the carbon; it is worthnoticing that carbon would act as a self-catalyzer. Micro Raman spectroscopy displays a high sensitivity for carbon, it has a high spacial resolution and, furthermore, the bonding state of carbon can be identified. ${ }^{9)-12)}$ Therefore, this technique has been adapted to analyzing the carbon deposition behavior on SOFC anodes. ${ }^{6), 13)-15)}$ In the present study, carbon deposition behavior on nickel particles at

\footnotetext{
Corresponding author: H. Kishimoto; E-mail: haruo-kishimoto@ aist.go.jp
}

the early stage of carbon deposition is analyzed by micro-Raman spectroscopy. Iida et al. reported that carbon deposition rate on the cermet anode is related to the oxide component in the anode; ${ }^{16)}$ carbon deposition rate for the Ni-SDC anode was faster than that for the Ni-YSZ anode at $1273 \mathrm{~K}$ under low humidified $\mathrm{CH}_{4}$ feeding. In addition, our group has reported that carbon deposition is suppressed on nickel film surface with ceria substrate whereas nickel surface on YSZ is not. ${ }^{17), 18)}$ In this study, two different oxides are used as the electrolyte material; one is a $8 \mathrm{~mol} \% \mathrm{Y}_{2} \mathrm{O}_{3}$ stabilized zirconia (YSZ), which is conventionally used as electrolyte material for SOFCs, and the other is $10 \mathrm{~mol} \%$ $\mathrm{GdO}_{1.5}$ doped ceria (GDC), which is considered to be a potential candidate for use in SOFCs. Carbon distribution for $\mathrm{Ni} / \mathrm{YSZ}$ and $\mathrm{Ni} / \mathrm{GDC}$ systems with sub-micrometer to several micrometer size nickel particles were visualized by using micro Raman spectroscopy combined with the model electrode technique, which is able to collect and discriminate information on carbon deposited on Ni particles and oxide surfaces as functions of oxide substrate and nickel particle size.

\section{Experimental}

The electrolyte disks were prepared from $8 \mathrm{~mol} \% \mathrm{Y}_{2} \mathrm{O}_{3}-$ $92 \mathrm{~mol} \% \mathrm{ZrO}_{2}$ (YSZ, Tosoh Co., Japan) and $10 \mathrm{~mol} \% \mathrm{GdO}_{1.5^{-}}$ $90 \mathrm{~mol} \% \mathrm{CeO}_{2}$ (GDC, Anan Kasei Co., Japan) powders. The powders were shaped into disks by uni-axial pressing and followed by cold isostatic pressing (CIP) at $390 \mathrm{MPa}$. The YSZ and the GDC were sintered at $1673 \mathrm{~K}$ for $5 \mathrm{~h}$ and at $1673 \mathrm{~K}$ for $8 \mathrm{~h}$ in air, respectively. Both surfaces of the sintered disks were polished with diamond slurry $(1 \mu \mathrm{m})$. Sample dimensions were about $11 \mathrm{~mm}$ in diameter and $0.3 \mathrm{~mm}$ in thickness. Nickel film was prepared by RF sputtering at room temperature onto the polished surface of the electrolyte disks. Masks resembling a keyhole were used to deposit $\mathrm{Ni}$ films with a clearly defined shape. The thickness of sputtered film was about $0.3 \mu \mathrm{m}$.

The samples were heated from room temperature to $863 \mathrm{~K}$ under flowing of a $1 \% \mathrm{H}_{2}-\mathrm{Ar}$ mixture gas. At this point, the gas was changed to dry $4.9 \% \mathrm{CH}_{4} / \mathrm{Ar}$ mixture and annealed for 

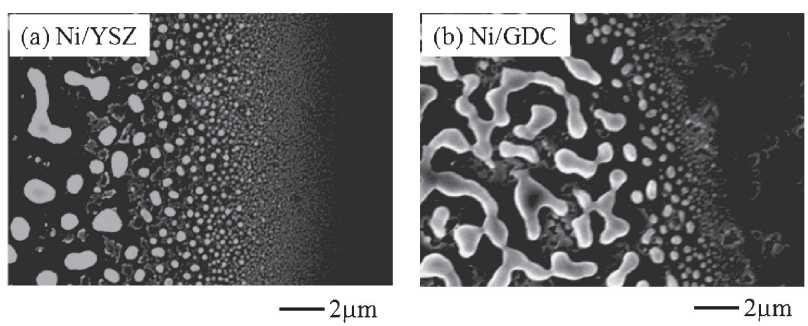

Fig. 1. SEM images for the samples after carbon deposition treatment. (a) the Ni/YSZ system and (b) the Ni/GDC system. Bright particles correspond to the sintered nickel.

$10 \mathrm{~min}$. Since no evidence for carbon deposition was detected at $863 \mathrm{~K}$ according to in-situ optical microscope monitoring, the samples were re-heated to $933 \mathrm{~K}$ after gas was re-changed to $1 \% \mathrm{H}_{2}-$ Ar. At $933 \mathrm{~K}$, sample was re-annealed under dry $4.9 \%$ $\mathrm{CH}_{4} / \mathrm{Ar}$ for $10 \mathrm{~min}$ and then cooled to room temperature under $1 \% \mathrm{H}_{2}-\mathrm{Ar}$ flow. The annealed sample surface was analysed by scanning electron microscopy (SEM, VE-7800, KEYENCE Co., Japan). After annealing, fine nickel particles in film was sintered into larger particles as shown in Fig. 1.

Carbon distribution was analysed by micro-Raman spectroscopy (NRS-3100, JASCO Co., Japan) at room temperature. The detected spectral range was about 1000 to $1900 \mathrm{~cm}^{-1}$ with the resolution less than $1 \mathrm{~cm}^{-1}$. The spectra were excited by the $532 \mathrm{~nm}$ wavelength and irradiation laser power was reduced to about $5 \mathrm{~mW}$ by using a Neutral Density (ND) filter to avoid the combustion of carbon by focused laser. The laser beam was focused on the sample by using an $\times 100$ objective lens to a diameter of about $2 \mu \mathrm{m}$. The sample was mounted on an $X-Y-Z$ motor stage with an autofocusing function. During a Raman mapping, the full spectra for each point were obtained. The area of the carbon distribution was visualized by analysing the integrated wavenumber range $\left(1250-1675 \mathrm{~cm}^{-1}\right)$ with background subtraction.

\section{Results and discussion}

Figures 1(a) and 1(b) shows SEM images for annealed samples of the Ni/YSZ and the Ni/GDC systems, respectively. The morphologies observed are almost the same for both systems. The nickel films on the electrolytes sintered during the heat treatment. The morphology of sintered nickel (bright particles in Fig. 1) gradually changed from the edge towards the inner part of sputtered nickel film. Particle size was less than several ten nanometres in diameter at the vicinity of the film edge and becomes $1 \mu \mathrm{m}$ width and several micrometer length at the inner part.

Figure 2(a) shows Raman spectra for the Ni/YSZ system. The spectrum from the nickel surface shows two intense peaks at 1353 and $1593 \mathrm{~cm}^{-1}$. These peaks appeared after annealing under dry methane. Raman peaks corresponding to carbon appear at around $1350 \mathrm{~cm}^{-1}$ and around $1600 \mathrm{~cm}^{-1}$; those peaks are identified as D-band (disorder related peak) and G-band (graphite related peak), respectively. ${ }^{9)-12)}$ The carbon deposited after annealing is identified as disordered carbon because the intensity of the D-band peak is stronger than that of the G-band peak. ${ }^{9)-12)}$ No carbon peak was observed on the surface of the YSZ. Figure 3(a) shows the intensity map of deposited carbon on $\mathrm{Ni} / \mathrm{YSZ}$ system. The map represents the integrated intensity of the sum of G-band peak and D-band peak in $20 \mu \mathrm{m} \times 60 \mu \mathrm{m}$ grid closed to the Ni film edge. The Raman data was obtained from $2 \mu \mathrm{m}$ contiguous spots across the whole grid. The carbon peaks was observed on the nickel sputtered area although no intensity

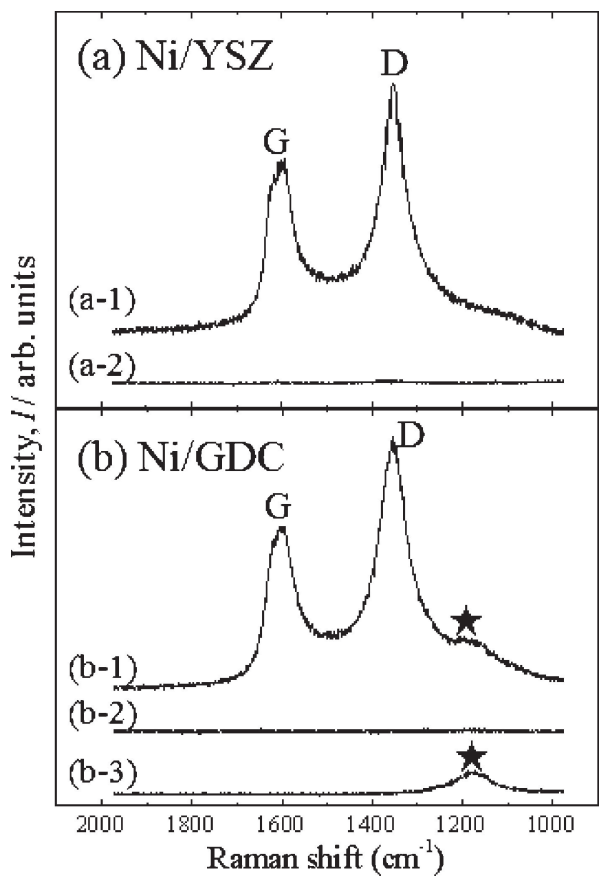

Fig. 2. Raman spectra obtained from the sample surface after carbon deposition treatment. (a) the Ni/YSZ system and (b) the Ni/GDC system. (a-1) Ni surface, (a-2) YSZ surface, (b-1) the surface along the edge of Ni film (with less than sub-micrometer size nickel particles), (b-2) the surface of nickel particle with micrometer size, and (b-3) GDC surface, respectively. Solid star is the peak from the GDC.

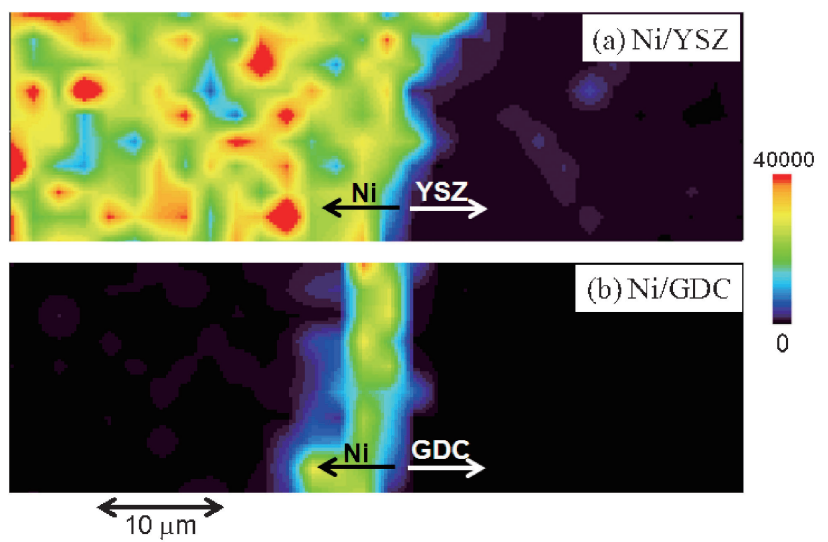

Fig. 3. Carbon distribution map for the sample surface after carbon deposition treatment. (a) the Ni/YSZ system and (b) the Ni/GDC system. The maps were obtained by analysing the integrated wavenumber range $\left(1250-1675 \mathrm{~cm}^{-1}\right)$ with background subtraction in the grid of $20 \times 60 \mu \mathrm{m}$ in the vicinity of the Ni film edge. The Raman data was measured in $2 \mu \mathrm{m}$ intervals.

was observed on the YSZ surface. The carbon distribution shows characteristic patterns like island, and it correspond to nickel particles distribution as shown in Fig. 1(a). This suggests that catalytic activity of nickel metal is required for decomposition reaction of methane for the $\mathrm{Ni} / \mathrm{YSZ}$ system. ${ }^{7), 8)}$

The procedure for visualization of carbon distribution is also adopted for the Ni/GDC system. Figure 3(b) shows the carbon distribution map for the $\mathrm{Ni} / \mathrm{GDC}$ system represented from the Raman spectra. An example of Raman spectra for the Ni/GDC system is shown in Fig. 2(b). On the nickel surface, at where the peak from GDC was not observed, peaks from carbon were not 
observed. Interestingly enough, carbon was observed only in the $5 \mu \mathrm{m}$ width along the edge of Ni film as shown in Fig. 3(b). The observed Raman spectra for deposited carbon [Fig. 2(b-1)] were essentially the same as that for the Ni/YSZ system. The nature of the carbon deposited at the early stage is the same between the $\mathrm{Ni}$ /YSZ system and the Ni/GDC system although deposited area was different between these two systems.

The difference of carbon distribution on Ni particles can be visually and clearly presented both for the Ni/YSZ system and the Ni/GDC system. Carbon deposition was observed on the whole nickel surface for the Ni/YSZ system. On the other hand, carbon deposition is limited on the nickel particles with submicron diameter for the Ni/GDC system. Carbon deposition was suppressed on the large nickel particles with GDC substrate. These results are essentially the same as our previous works reported by Horita et al. using secondary ion mass spectrometry (SIMS) analysis ${ }^{17)}$ and reported by Yoshinaga et al., using microRaman spectroscopy. ${ }^{18)}$ It is also suggested that the surface of nickel sputtered on YSZ substrate is oxidized under $\mathrm{CH}_{4}-\mathrm{H}_{2} \mathrm{O}-$ $\mathrm{O}_{2}$ condition. ${ }^{17)}$ In contrast, Raman peak from $\mathrm{NiO}$ was not observed in the present results even though Raman spectroscopy is sensitive for the surface. The present experimental condition, under dry methane at $933 \mathrm{~K}$, is quite different from that reported by Horita et al., under wet condition at $1073 \mathrm{~K}$. It is clear that nickel surface property is affected by oxide substrate and it is clearly different between YSZ and GDC whether water vapour exists or not. Because most of nickel particles are as large as submicron to several-micrometer in this study, the nickel should show the similar properties as bulk nickel because an electronic interaction at the nickel/oxide substrate heterojunction is not effective against nickel surface condition for such a thick particle. Therefore, the oxide substrate effect on the nickel surface is related to the mass transport behaviours; mass transport from oxide surface to nickel surface via gas phase, that form the TPB to nickel surface by spillover, or that across the nickel/ oxide substrate interface. One of the possibilities is that the difference of proton solubility in oxides ${ }^{19)-21)}$ affects the adsorption process on nickel surface according to the hydrogen transport across the nickel/oxide interface. As a result, the activity of adsorbed molecules (atoms), such as $\mathrm{OH}$, on nickel surface are different between $\mathrm{Ni} / \mathrm{YSZ}$ system and $\mathrm{Ni} / \mathrm{GDC}$ system although the hydrogen concentration (activity) in the nickel metal is the same between these two systems.

It is also interesting that the carbon deposition for the Ni/GDC system was observed only in the $5 \mu \mathrm{m}$ width along the Ni film edge. This phenomenon could not be observed in previous reports. ${ }^{17), 18)}$ In this region, due to nickel sintering, the size of nickel particle progressively changes from several ten nanometres to sub-micrometer in the direction towards the nickel film inner area. The present result suggests that the surface condition of the nickel particle is different between the micrometer-sized particles and particles with less than sub micrometer size for the $\mathrm{Ni}$ /GDC system. This may be related to the surface tension of nickel particles. For the Ni/GDC system, surface tension of nickel particle with sub micrometer size may be different from that with micrometer size. As a result, surface condition of nickel particle becomes different. A possibility is that orientation of nickel lattice was different, and the other possibility is difference of electronic state of nickel surface between sub micrometer size and micrometer size nickel particles. At this point, no clear reason can be invoked to explain these phenomena. Efforts to reveal the effect on the nickel surface condition and interactions of electrolyte materials with nickel particles are required.

\section{Conclusion}

Carbon distribution maps on nickel particles were obtained by micro Raman spectroscopy. The difference of carbon distribution between the Ni/YSZ system and the Ni/GDC system can be clearly visualized with a spacial resolution of $2 \mu \mathrm{m}$. Deposited carbon, which was identified as an disordered carbon phase, was deposited on the whole nickel surface for the Ni/YSZ. Whereas, for the Ni/GDC, amorphous carbon was only observed in a $5 \mu \mathrm{m}$ width region along the Ni film edge, in where nickel particle size was in the sub-micrometer range.

\section{References}

1) N. Q. Minh, J. Am. Ceram. Soc., 76, 563-588 (1993).

2) J. Mizusaki, H. Tagawa, T. Saito, K. Kamitani, T. Yamamura, K. Hirano, S. Ehara, T. Takagi, T. Hikita, M. Ippommatsu, S. Nakagawa and K. Hashimoto, J. Electrochem. Soc., 141, 2129-2134 (1994).

3) J. Mizusaki, H. Tagawa, T. Saito, T. Yamamura, K. Kamitani, K. Hirano, S. Ehara, T. Takagi, T. Hikita, M. Ippommatsu, S. Nakagawa and K. Hashimoto, Solid State Ionics, 70/71, 5258 (1994).

4) A. Bieberle, L. P. Meier and L. J. Gauckler, J. Electrochem. Soc., 148, A646-A656 (2001).

5) T. Kawada, K. Yashiro, T. Taura, K. Takeda, A. Kaimai, H. Matsumoto, J. Mizusaki and H. Yugami, in Proc. Fuel Cell Science, Engineering and Technology-2004, Ed. by R. K. Shah and S. G. Kandlikar (2004) p. 53, ASME (2004.6.14-2004.6.16).

6) K. Yashiro, K. Takeda, T. Taura, T. Otake, A. Kaimai, Y. Nigara, T. Kawada and J. Mizusaki, in Proc. Solid Oxide Fuel Cells VIII, Ed. by S. C. Singhal and M. Dokiya, PV 2003-7, The Electrochemical Society Proceedings Series, Pennington, NJ (2001) p. 714.

7) H. Kim, S. Park, J. M. Vohs and R. J. Gorte, J. Electrochem. Soc., 148, A693-A695 (2001).

8) T. Takeguchi, Y. Kani, T. Yano, R. Kikuchi, K. Eguchi, K. Tsujimoto, Y. Uchida, A. Ueno, K. Omoshiki and M. Aizawa, J. Power Sources, 112, 588-595 (2002).

9) J. Robertson, Mater. Sci. Eng., R37, 129 (2002).

10) M. S. Dresselhaus, G. Dresselhaus, R. Saito and A. Jorio, Phys. Rep., 409, 47-99 (2005).

11) L. G. Cançado, K. Takai, T. Enoki, M. Endo, Y. A. Kim, H. Mizusaki, A. Jorio, L. N. Coelho, R. Magalhães-Paniago and M. A. Pimenta, Appl. Phys. Lett., 88, 163106-1-163106-3 (2006).

12) M. A. Pimenta, G. Dresselhaus, M. S. Dresselhaus, L. G. Cançado, A. Jorio and R. Saito, Phys. Chem. Chem. Phys., 9, 1276-1291 (2007).

13) M. B. Pomfret, J. C. Owrutsky and R. A. Walker, J. Phys. Chem. B, 110, 17305-17308 (2006).

14) M. B. Pomfret, J. Marda, G. S. Jackson, B. W. Eichhorn, A. M. Dean and R. A. Walker, J. Phys. Chem. C, 112, 5232-5240 (2008).

15) K. Yamaji, H. Kishimoto, Y. Xiong, T. Horita, N. Sakai, M. E. Brito and H. Yokokawa, Solid State Ionics, 179, 1526-1530 (2008).

16) T. Iida, M. Kawano, T. Matsui, R. Kikuchi and K. Eguchi, J. Electrochem. Soc., 154, B234-B241 (2007).

17) T. Horita, H. Kishimoto, K. Yamaji, N. Sakai, Y. Xiong, M. E. Brito, H. Yokokawa, M. Rai, K. Amezawa and Y. Uchimoto, Solid State Ionics, 177, 3179-3185 (2006).

18) M. Yoshinaga, H. Kishimoto, K. Yamaji, Y.-P. Xiong, M. E. Brito, T. Horita and H. Yokokawa, Solid State Ionics, in press. doi:10.1016/j.ssi.2010.05.003

19) N. Sakai, K. Yamaji, Y.-P. Xiong, H. Kishimoto, T. Horita and H. Yokokawa, J. Electroceram., 13, 677-682 (2004).

20) H. Yokokawa, T. Horita, N. Sakai, K. Yamaji, M. E. Brito, Y.-P Xiong and H. Kishimoto, Solid State Ionics, 174, 205-221 (2004).

21) H. Yokokawa, T. Horita, N. Sakai, K. Yamaji, M. E. Brito, Y.-P. Xiong and H. Kishimoto, Solid State Ionics, 177, 1705-1714 (2006). 